\title{
EDITORIAL
}

\section{La Constitución Europea renace de sus cenizas: el Tratado de Lisboa'}

\section{Consejo de Redacción}

\author{
"Hoy existe una lucha por Europa" \\ (Anthony Giddens)
}

Palabras clave: Unión Europea, Tratado de Lisboa, modelo europeo, mayoría cualificada, instituciones de la UE, futuro de la Unión.

Key words: European Union, Treaty of Lisbon, European model, Qualified Majority, EU Institutions, The Future of the EU.

\section{Introducción: un nuevo texto ha sido aprobado}

El Consejo Europeo de Lisboa del 18 y 19 de octubre de 2007, tras intensos debates, aprobó el texto de "Tratado por el que se reforma el Tratado de la Unión Europea y el Tratado que establece la Comunidad Europea". La firma oficial tuvo lugar el 13 de diciembre de 2007 en Lisboa, cerrando así el semestre de presidencia portuguesa.

Este acontecimiento ha tenido relativamente poco impacto en la opinión pública, contrastando, por cierto, con el eco mediático que tuvo el proceso de elaboración, aprobación y sobre todo azarosa ratificación de la llamada Constitución Europea, que el presente Tratado viene a reemplazar ${ }^{2}$. Asimismo, a nuestro entender, hasta

\footnotetext{
1 Texto cerrado el 31 de marzo de 2008.

2 En un anterior artículo editorial abordamos el tema bajo una óptica específica: el debate sobre las raíces cristianas del proyecto europeo y la discusión de si esa mención debió o no ser incluida en el texto. Cfr. Consejo de RedACCIÓN (2004), "Más allá de la Constitución: Europa entre las raíces cristianas
} 
el momento de escribir estas líneas, han sido escasos los análisis sosegados y las aportaciones reflexivas, al menos en el contexto español ${ }^{3}$.

Como nuestros lectores conocen, el "no" en los referéndum francés y neerlandés a aquel "Tratado por el que se establece una Constitución para Europa" impedía su entrada en vigor, para la que se requería -como en cualquier Tratado- la unánime ratificación de todos los Estados miembros. Por ello, a pesar de que 16 países ya habían ratificado el texto ${ }^{4}$ (sea en referéndum y posterior ratificación parlamentaria, como en el caso español, sea mediante votación parlamentaria), los resultados negativos citados y las reticencias de algunos otros países que aún no lo habían ratificado, hacían necesaria una profunda revisión del tema. Desde luego, era inimaginable que el mismo texto, sin cambios sustanciales, pudiera ser sometido a nuevo referéndum en Francia y en los Países Bajos.

Este artículo editorial tiene unas pretensiones modestas. Queremos explicar sencillamente el estado de la cuestión: comenzamos analizando brevemente lo sucedido con el texto anterior; recorreremos luego el proceso de elaboración del nuevo texto destacando los cambios que se han introducido sobre el anterior; presentaremos a continuación algunas reflexiones acerca de lo sucedido; terminaremos con algunas referencias críticas sobre el proceso y el modelo, que van más allá de este incidente (uno de tantos en el largo camino de la construcción europea), y con una relación de los retos de fondo que, en nuestra opinión, se plantean a la UE en la actualidad.

\section{Los antecedentes: el camino azaroso de la Constitución Europea}

El 30 de octubre de 2004 se firmó en Roma el texto del proyecto de Constitución europea (propiamente: "Tratado por el que se establece una Constitución para Europa"), que había sido aprobado por los Jefes de Estado y de Gobierno de los 25 países miembros en la cumbre del mes de junio anterior. La firma tuvo lugar

y la laicidad", Revista de Fomento Social, n 236, 727-749.

3 Una notable excepción: el excelente comentario de Francisco AldeCOA LUZARRAGa (2007) "Regreso al futuro: el Tratado de Reforma", El País, 19 de octubre, 15-16.

${ }^{4}$ Otros dos países (Alemania y Eslovaquia) "casi lo habían ratificado", en cuanto hacían falta algunos requisitos para ello. Quedaban pues siete países sin ratificarla, a saber: Portugal, Irlanda, Reino Unido, Polonia, Dinamarca, Suecia y República Checa. 
precisamente en la misma sala de los Orazi y Curiazi del Capitolio romano donde hacía más de cincuenta años se habían firmado los Tratados de Roma, impulsados por los padres de Europa.

Prescindiendo de otros precedentes más lejanos, el punto de partida del proceso se sitúa en la cumbre de Jefes de Gobierno (Conferencia Intergubernamental ${ }^{5}$, técnicamente hablando) del 14 y 15 de diciembre de 2001 en Laeken (Bélgica). En ella se tomó la decisión de confiar la redacción del borrador de Constitución a un órgano consultivo nuevo -no previsto en el marco institucional comunitario- llamado "Convención", presidida por el expresidente francés Valéry Giscard d'Estaing. Dicha Convención trabajó intensamente entre diciembre de 2001 y julio de 2003 en que se presentó el borrador de texto. Según Giscard:

"El objetivo de la Convención fue proponer para la Unión Europea un marco y unas estructuras adecuados a la evolución del mundo, a las necesidades de los ciudadanos europeos y al futuro desarrollo de la Unión Europea.

La Convención ha constituido una innovación... reunió a representantes de los gobiernos, de los parlamentos nacionales, del Parlamento Europeo y de la Comisión Europea.

Sus deliberaciones fueron públicas, y los ciudadanos pudieron consultar sus documentos. Por otra parte, las organizaciones de la sociedad civil tenían la posibilidad de contribuir a los debates, especialmente inscribiéndose para ello en el Foro"b.

Este texto preparado por la Convención fue la base del trabajo de la Conferencia Intergubernamental, celebrada en Roma el 4 de octubre de 2003. No fueron muchas las modificaciones que se introdujeron. Pero algunas eran de cierta entidad, en especial en lo relativo al tema estratégico del reparto del poder en el Consejo de Ministros. Estos cambios dieron ocasión a que se consolidaran determinados bloques y desacuerdos sobre el contenido del texto.

Se recordará la posición de España (bajo la presidencia de Aznar) y Polonia contraria a que se modificaran las previsiones al respecto del Tratado de Niza, esencialmente por la eliminación del voto ponderado en el Consejo de Ministros,

\footnotetext{
${ }^{5}$ Formalmente, las propuestas de modificación de los Tratados las hacen los propios Estados, no la Unión en cuanto tal, que no tendría competencias para ello. Por eso se llama a esos procesos "conferencias intergubernamentales", formadas por países enteramente soberanos, donde, por supuesto, se aplica la regla de la unanimidad.

${ }^{6}$ Cfr. la página web de la Convención Europea que elaboró el primer borrador de la Constitución Europea. http://european-convention.eu.int/. Cfr. artículo de V. Giscard d'Estaing en El País, 14 de enero de 2003.
} 
sistema que permitía a esos dos países disponer de un poder relativo superior al de su población. Por este motivo, la siguiente sesión de la Conferencia Intergubernamental, celebrada los días 28 y 29 de noviembre de 2003 en Nápoles, dejó bien patente la gran dificultad existente para llegar a consenso y se llegó a pensar en la posibilidad de un fracaso del proyecto de la Constitución. Este pesimismo dominante se confirmó en la siguiente reunión del Consejo Europeo (12 y 13 de diciembre de 2003) en Bruselas, donde el borrador fue rechazado al no alcanzar el consenso necesario. A corregir la dinámica de desencuentro contribuyó decisivamente el cambio de partido gobernante en España a raíz de las elecciones del 14 de marzo de 2004, sólo tres días después del brutal atentado de Madrid. El nuevo presidente español, Rodríguez Zapatero, adoptó una posición más flexible. El cambio de actitud de España arrastró a otros protagonistas de los anteriores enfrentamientos y se pudo lograr un acuerdo sobre un texto definitivo en la cumbre de Bruselas de junio 2004. De ahí que se llegara a la solemne firma del nuevo texto, por parte de todas las delegaciones nacionales en octubre de 2004 . Se abría así el largo período de ratificación, al que ya hemos aludido, que debía durar como máximo dos años.

El rechazo recibido por ese texto en los citados referéndum francés y holandés ha sido objeto de muchas y divergentes interpretaciones. Paradójicamente, las posiciones de la izquierda más radical y de la derecha más reaccionaria coincidieron en su oposición a la llamada Constitución. Parece claro que una parte importante de las fuerzas de la izquierda y de los movimientos sociales alternativos se oponían a aquel Tratado porque consideraban que consagraba un modelo neoliberal y capitalista que se desviaba de los objetivos de cohesión y solidaridad. En un contexto globalizado, este "nuevo modelo europeo" se caracterizaría por desmantelar el Estado social en aras de recuperar la competitividad perdida, principalmente respecto al gigante norteamericano. Por otro lado, las fuerzas de la derecha, defendiendo posturas fuertemente nacionalistas, miraban con reticencia entre otras cosas los atisbos de pérdida de soberanía y los indicios de "federalismo" contenidos en el Tratado. Si a eso añadimos los problemas internos derivados de la coyuntura política de esos países y una campaña anterior a la consulta particularmente polémica y "caliente", la conclusión quedaba servida.

Además, al menos en el caso francés, buena parte de los defensores del "no" agitaron el fantasma de la competencia de los países del Este, nuevos miembros, mediante el temido "dumping social", lo que se resumió en la conocida amenaza del "fontanero polaco": un supuesto desembarco masivo de mano de obra de esos países, que haría llegar un gran número de inmigrantes a quitar los puestos de trabajo a los nacionales franceses, ofreciendo sus servicios con bajos salarios. 
Otros países como Gran Bretaña, reticente desde el principio a la Constitución a pesar de que Tony Blair, su Jefe de Gobierno, lo firmó en el solemne citado acto romano, temían la convocatoria del referéndum que tenía grandes posibilidades de resultar también negativo, dada la postura tradicionalmente euroescéptica de buena parte del electorado del Reino Unido. Y los británicos no son los únicos euroescépticos en la nueva Europa de 27 países... Por último, y no menos importante, fue seguramente un error estratégico la inclusión del término "Constitución" en el propio título del Tratado, lo que en estricto rigor no era.

En las conclusiones, de forma más general, volveremos sobre el significado de los "referéndum fallidos". De momento reconozcamos que todas estas circunstancias hacían evidente que el texto de la Constitución no podría ser adoptado sin hacer cambios importantes. A esa tarea habrían de dedicarse los meses siguientes, transcurrido un tiempo prudencial de silencio para que el ambiente se sosegara y los ánimos se calmaran.

\section{El nuevo texto: un "Tratado de reformas"}

Más de dos años pasaron hasta que, entrado ya el año 2007, la tarea fue, por fin, retomada. Le correspondió hacerlo a la Presidencia alemana (primer semestre de 2007), aprovechando el reconocido liderazgo de Angela Merkel. Se partía ahora de un planteamiento muy realista: a la vista de lo sucedido, quedaba claro que había que "bajar de nivel" en las pretensiones del Tratado, moderando sus entusiasmos europeístas, y que un nuevo acuerdo sólo sería posible si se abandonaban los elementos más "federalistas" del proyecto anterior. En el apartado siguiente volveremos sobre esas diferencias.

Así pues, la presidencia alemana propuso un nuevo borrador en el Consejo de la Unión Europea el 19 de mayo de 2007. La propuesta fue presentada tras una serie de reuniones de trabajo entre la Presidencia y los delegados de los demás Estados miembros a lo largo de los primeros meses del año 2007. También ese borrador fue objeto de controversia, ya que algunos países (como Polonia) adoptaron posiciones intransigentes en algunas materias de su interés; fue preciso realizar concesiones y arbitrar algunas excepciones; pero, al final, la capacidad de convicción y de negociación de la Canciller alemana superó todos los obstáculos.

Siguiendo el itinerario previsto, fue Portugal, tras asumir la presidencia de la UE durante la segunda mitad del 2007, quien lanzó una nueva Conferencia Intergubernamental (los días 23 y 24 de julio), para perfilar la redacción del texto ya 
consensuado en lo esencial, coincidiendo con la reunión de Ministros de Asuntos Exteriores.

A esta Conferencia Intergubernamental le correspondió, por tanto, la redacción del borrador final del nuevo Tratado. Para ello se había emitido, en la cumbre de la UE de junio de 2007 en Bruselas (la última bajo la Presidencia alemana), un mandato para las negociaciones, que trataba de especificar el contenido del Tratado en cierto detalle, para evitar que los negociadores entraran en debates políticos y limitar su trabajo al aspecto técnico del borrador. En la Conferencia Intergubernamental participaron, además de todos los países miembros, sendas representaciones de la Comisión y del Parlamento Europeos ${ }^{7}$.

El nuevo Tratado fue presentado en la cumbre del 18 de octubre en la ciudad de Lisboa, con la intención de que fuera firmado por los líderes nacionales antes de que finalizara el año 2007. Y así ocurrió efectivamente: el "Tratado por el que se reforma el Tratado de la Unión Europea y el Tratado que establece la Comunidad Europea" fue firmado en la cumbre de Lisboa el 13 de diciembre de 2007.

Como cualquier tratado, será necesaria la ratificación por parte de todos y cada uno de los Estados miembros para que pueda entrar en vigor. Ese proceso debería tener lugar a lo largo del año 2008 con el objetivo de que el texto entre en vigor el 1 de enero de 2009. Sin embargo, en esta ocasión, por lo que se sabe, parece que la gran mayoría de los países piensan someter el texto solamente a ratificación parlamentaria ${ }^{8}$.

En esencia todo este proceso se ha materializado en que la UE ha descartado los planes de promulgar "una especie de" Constitución, decidiendo, en vez de eso, enmendar los dos tratados fundamentales vigentes". El texto resultante, el citado "Tratado de Reforma", es sumamente farragoso y de difícil lectura, pues su género

\footnotetext{
7 Los parlamentarios europeos representaban a las tres fuerzas políticas mayoritarios: el alemán Elmar Brok (del Partido Popular Europeo), el español Enrique Barón (del Partido Socialista Europeo) y el británico Andrew Duff (de la Alianza de Liberales y Demócratas por Europa).

${ }^{8}$ Nos consta que Irlanda será una excepción, ya que su gobierno anunció que piensa convocar un referéndum; según los indicios la aprobación no debería presentar especiales dificultades, como ocurrió en 2001 con el Tratado de Niza. Parece también que Dinamarca y Portugal podrían someterlo a referendum; en el caso de Dinamarca las perspectivas de aprobación pueden ser algo más dudosas.

9 De hecho, ésta era la fórmula defendida enérgicamente, entre otros, por el gobierno británico, que le permitirá aprobarlo sin necesidad de recurrir a un aventurado referéndum.
} 
literario consiste en añadidos, supresiones y modificaciones, artículo por artículo, de los preceptos previos del "Tratado de la Unión" y del "Tratado que establece la Comunidad Europea". Bajo este formato (que es el que se aprobó el 13 de diciembre y será ratificado por todos los países) una lectura "de corrido" no tiene ningún sentido, puesto que es ininteligible sin tener delante los textos previos que son objeto de enmienda. Por ello, es indispensable disponer de una versión consolidada ${ }^{10}$ que sí puede ser objeto de una lectura continua.

Para que nuestros lectores se hagan una idea exacta, añadiremos que el resultado de ese "Tratado de Reforma" supone una nueva versión de los dos anteriores tratados citados, que ahora se llamarán:

1. El "Tratado de la Unión Europea", que modifica y sustituye al anterior del mismo nombre, procedente del Tratado de Maastricht (1992).

2. El "Tratado de funcionamiento de la Unión Europea", un título nuevo que contiene el largo texto reformado (con todas las reformas anteriores consolidadas) del Tratado que establece la Comunidad Europea (Tratado de Roma de 1957).

\section{Comparación con el anterior texto: ¿qué cambia? ¿qué permanece?}

¿En qué se parecen el Tratado de Reforma y la Constitución abortada? Según el profesor Aldecoa ${ }^{11}$, el $90 \%$ del contenido del texto anterior ha sido preservado.

Quizá lo más significativo es que la Constitución pretendía reemplazar todos los Tratados anteriores de la UE por uno nuevo, mientras que los nuevos Tratados sólo reforman los anteriores. Otra diferencia significativa es la eliminación de algunas

\footnotetext{
${ }^{10}$ Los lectores interesados disponen de un excelente trabajo realizado por José Martín y Pérez de Nanclares, Catedrático de Derecho Internacional Público, y Mariola Urrea Correa, Profesora Contratada Doctor de Derecho Internacional Público, ambos de la Universidad de La Rioja, para el Real Instituto Elcano. Se trata de la primera versión en castellano del texto consolidado del Tratado de la Unión Europea y del Tratado que establece la Comunidad Europea con las modificaciones introducidas por el Tratado de Reforma. Los textos se encuentran en la web del Instituto: <www.realinstitutoelcano.org>. Cfr. la edición en papel: Martín y Pérez de Nanclares, J. y Urrea Correa, M. (2008) Tratado de Lisboa, Madrid, Real Instituto Elcano y Marcial Pons
}

${ }^{11}$ Art. cit. en nota 2. 
referencias a elementos simbólicos "supranacionales", como son la bandera, el himno, el lema (aunque siguen existiendo) etc. Otras muchas cosas, sin embargo, han salido ilesas.

También ha desaparecido del Tratado la Carta de los Derechos Fundamentales que incorporó la Constitución. Ni siquiera ha quedado como anejo. Sólo existirá una referencia, que hace a aquélla legalmente obligatoria. Este es otro elemento importante que "rebaja" las pretensiones constitucionales del nuevo texto ${ }^{12}$. Por su parte, Irlanda y el Reino Unido tienen opciones de excepción a las políticas europeas en materia de asilo, visados e inmigración: el "Tratado de Reforma" les da derecho de excepción en lo referente a justicia y asuntos internos.

En términos generales, el nuevo tratado profundiza la cooperación en algunas tareas y la extiende a otras nuevas ${ }^{13}$. Algunas voces críticas destacan que el Tratado incentiva a los gobiernos de la UE a aumentar el gasto militar (por la consolidación de la Agencia Europea de Defensa, creada en 2004) y a promover el libre comercio (esto último, ciertamente, no es ninguna novedad en la UE).

Sin embargo, el texto aprobado mantiene muchos de los cambios que la Constitución introdujo. Destacamos los más importantes:

- Pese a que la Presidencia de la Unión seguirá siendo rotativa y los Estados miembros la ocuparán cada seis meses, habrá un Presidente fijo elegido por el Consejo Europeo por mayoría cualificada, cuyo mandato será por un periodo de dos años y medio.

- Se creará la figura no de un Ministro de Asuntos Exteriores sino de un Alto Representante de la Unión para Asuntos Exteriores y Política de Seguridad. En ella se combinan las responsabilidades del Jefe de Política Exterior y Seguridad Común (Javier Solana) y de la Comisaria de Relaciones Exteriores (Benita

\footnotetext{
${ }^{12}$ En este mismo tema de la Carta de Derechos Fundamentales, también Polonia y Dinamarca tienen algunas condiciones especiales; el anterior gobierno polaco de Kaczynski exigió no aplicar en su territorio polaco la Carta de Derechos Fundamentales, a la que el nuevo Tratado de Lisboa otorga carácter jurídico; en el caso de Dinamarca sus excepciones venían de antes. El Reino Unido, por su parte, ha recibido garantías escritas de que la Carta no puede ser usada por la Corte de Justicia Europea para alterar la legislación laboral británica así como otras leyes relativas a los derechos sociales. Es éste un tema debatido: no está clara la efectividad jurídica de esta cláusula.
}

${ }^{13}$ Pero de hecho, por lo que hemos podido consultar, existen opiniones divergentes sobre el alcance de las nuevas transferencias de poder a la UE. 
Ferrero-Waldner). De este modo se pretende dar a la Unión mayor peso en la escena mundial.

- La Comisión Europea quedará más reducida, ya que tendrá menos comisarios que países socios. A partir de 2014, cada país dejará, como hasta ahora, de enviar un comisario a Bruselas, y la Comisión pasará a estar formada por 18 miembros. Los Estados miembros tendrán que turnarse para estar presente en esta alta instancia.

- Otro importante avance consiste en la redefinición de la mayoría cualificada, uno de los temas más debatidos en la Unión. Ahora se establece en un mínimo del $55 \%$ de los miembros del Consejo que represente a Estados miembros que reúnan como mínimo el $65 \%$ de la población de la Unión. Pero esta medida no entrará en vigor hasta el 1 de noviembre de 2014. Y con una salvedad importante: el nuevo sistema no se aplicará hasta el 1 de abril de 2017 siempre que un miembro del Consejo exija que se aplique el sistema anterior. Además, tras Lisboa serán más los temas que el Consejo Europeo podrá decidir por mayoría, dejando de lado el freno que suponen las aprobaciones por unanimidad. Se suprime el poder de veto en cierto número de casos.

- Se asignan nuevos poderes a la Comisión Europea, al Parlamento Europeo y a la Corte Europea de Justicia. Especialmente importantes son las de este último órgano. También el Parlamento Europeo, el único órgano que los ciudadanos comunitarios votan directamente, gana en peso: la toma de decisiones la llevará a cabo conjuntamente con el Consejo, y no ya el Consejo en solitario; además elegirá al Presidente de la Comisión. Por otra parte, y para fortalecer los principios democráticos dentro de la Unión, con un millón de firmas los europeos podrán solicitar a la Comisión que elabore un proyecto de ley.

\section{Una valoración sobre el proceso y sobre el modelo europeo}

Pasamos a ofrecer, para ir concluyendo nuestra reflexión, tres consideraciones: las dos primeras, de índole más general, sobre el debate en curso acerca del proceso y el modelo europeo; la segunda, que dejamos para el apartado final, es un intento de síntesis acerca de algunos retos que, a nuestro juicio, tiene planteados la UE. 


\section{I. Sobre el proceso}

Una primera reflexión crítica que nos inspira todo lo sucedido es que ya no se pueden resolver los referéndum fallidos ignorando los resultados: ocurrió con Dinamarca para Maastricht, con Irlanda para Niza, con Francia y Países Bajos para el proyecto de Constitución. Rebajar y despreciar los argumentos que sustentan el "no" e ignorar ese dictamen, para volver a presentar lo mismo o casi, es una práctica dudosamente respetuosa con la democracia. Como ya diijimos, detrás del "no" había confusión y demagogia, pero también rechazo al liderazgo europeo y una enorme dosis de desinterés ciudadano. ¿No había que tomar muy en serio estos últimos datos?

Las numerosas cuestiones de fondo surgidas a lo largo de este debate hubieran sido igual de relevantes en el caso, no tan inverosímil, de que el "sí" hubiera triunfado, pero no es de recibo despreciar una larga serie de consultas fallidas y todo el debate alrededor de la última consulta a los europeos. La población vota con su criterio, más o menos ilustrado, y no es seguro que se equivoque más que sus políticos. No se pueden hacer avances significativos a estas alturas de la historia de la UE sin reforzar la participación de los ciudadanos. El Tratado de Lisboa se ha elaborado rechazando los tímidos intentos de participación de los ciudadanos, con los que sí se contó, en cambio, en la elaboración del proyecto de Constitución. ¿Significa esto que se piensa que la UE se puede hacer sin los ciudadanos?

Además, aprobar en 2007 medidas esenciales para que entren en vigor en el 2014 , no contribuye a que los ciudadanos se sientan identificados con el proyecto de UE. Seguramente que en época de frenazo o euroescepticismo hay que optar por soluciones pragmáticas al más puro estilo de la UE. Pero sería mejor que las aceptemos sin celebrarlo demasiado, reconociendo que atravesamos un momento bajo del proceso donde faltan verdaderos liderazgos ${ }^{14}$.

Efectivamente, ese tropiezo, ese "no" parcial, es también un síntoma de que la UE tiene una ausencia de liderazgo evidente. Estamos en un período de posiciones políticas mediocres (neoliberales o no neoliberales), que no han sido precisamente las bases sobre las que se ha construido el proyecto europeo. Los líderes actuales

\footnotetext{
${ }^{14} \mathrm{Al}$ momento de redactar estas líneas se anuncia la creación de un "comité de sabios", que será presidido por Felipe González, cuyo objetivo será trazar las líneas maestras para garantizar la "modernización del modelo europeo". Se trataría de dar respuesta a las demandas de los ciudadanos y asegurar la continuación del progreso económico, la estabilidad social, el desarrollo sostenido y la lucha contra el cambio climático. No es la primera vez que el proceso de integración europea intenta salir de sus atolladeros acudiendo a este tipo de fórmulas.
} 
fomentan un rebrote del intergubernamentalismo; hay una sensación de pérdida del tradicional empuje de la Comisión Europea, también sometida a liderazgos mediocres; diríase que los Jefes de gobierno eligen personas de cómodo o bajo perfil para no verse forzados a avanzar. El Parlamento gana progresivamente en funciones pero, aunque es difícil medir su trabajo, no está claro que refuerce los intereses de la integración europea. ¿̇Qué buena noticia ha venido de la UE en los últimos 5 años, más allá de la frustrada Constitución, o de la Estrategia para la competitividad de Lisboa, no exenta de voluntarismo y verbalismo? Se echa mucho de menos alguna propuesta innovadora, alguna señal de compromiso fuerte con algún tema de relevancia interna o externa.

Tampoco esto es algo nuevo. Porque ¿̇no es cierto que la construcción europea ha basado su éxito histórico en una serie de claves entre las cuales se encuentra el gradualismo? Todo se ha hecho poco a poco, porque no se puede ir más deprisa de lo que permiten las circunstancias históricas.

A pesar de todo ello hay que felicitarse porque el nuevo texto aprobado por los Jefes de Estado y de Gobierno salva la esencia de la frustrada Constitución. Si el $90 \%$ del contenido material del texto primitivo ha sido salvado, no se puede afirmar razonablemente -como han hecho tantos políticos y comentaristas- que "la Constitución está muerta".

Es cierto que en el camino se ha perdido una parte importante de un cierto "élan" europeísta, que reforzaba el concepto de ciudadanía europea y avanzaba -de forma muy tímida y casi vergonzante- en la línea de un cierto federalismo. Pero esa constatación no anula del todo las declaraciones que siguieron a la cumbre en que se logró el acuerdo, cuando la mayor parte de los Jefes de Estado y de Gobierno reconocieron que se preservaría el espíritu de la Constitución. Tal es también la cualificada opinión de Aldecoa, que compartimos:

"El rescate de la Constitución en forma de Tratado de Reforma recoge en gran parte la ambición de los momentos más álgidos del proceso constituyente (Laeken, la Convención...) que han supuesto un impulso nuevo para la construcción europea. La consecuencia efectiva de los noes francés y neerlandés no ha sido la muerte de la Constitución sino un retraso de tres años en la vigencia de lo aprobado. Impulso y proceso político continúan: el Parlamento Europeo ya ha anunciado que, en cuanto entre en vigor el nuevo tratado, presentará "nuevas propuestas sobre un acuerdo constitucional para la Unión". Lo que empieza ya a ser una opinión compartida es que los avances futuros de la integración europea seguirán la senda de la diferenciación"15.

${ }^{15}$ Art. cit. en nota 2. 
Precisamente en las reflexiones siguientes, y en el apartado conclusivo sobre los retos finales, volveremos sobre estas ideas.

\subsection{Sobre el modelo europeo}

Ya en el debate sobre la Constitución europea interfirió con frecuencia la discusión acerca del llamado "modelo social europeo". Había quienes lo acusaban (especialmente algunos fervientes partidarios del "no" a la Constitución) de que consagraba el modelo neoliberal. Pues bien, conviene recordar que ni aquel texto ni el nuevo que acaba de ser aprobado, modifican nada al respecto. Como ha explicado con lucidez Jacques Delors, frente a los que encuentran a Europa "demasiado liberal", lo que seguramente es cierto (dependiendo de lo que se entienda por "liberal" y por "demasiado"...), ello no es algo que dependa ni de la Constitución, ni de los Tratados anteriores ni, con más razón aún, del que acaba de aprobarse:

"Es una cuestión de mayorías, no es algo ligado al tratado. Actualmente, Europa está marcada por un pensamiento dominante de tendencia liberal, que yo cuestiono en numerosos aspectos. Lo que hay que hacer es luchar políticamente, según las reglas del juego, a nivel de los gobiernos, del Parlamento europeo, de los actores sociales" 16.

No era la llamada Constitución europea, ni lo será ningún Tratado posterior, quienes vayan a definir el modelo social de los países europeos. Esto es algo que depende esencialmente de las soberanías nacionales expresadas en las opciones políticas ganadoras de los comicios en cada país.

Es verdad, como dice Delors, que es el entorno el que es "liberal" y no la UE. Sin embargo hay que reconocer que la Estrategia de Lisboa y las previsiones financieras parecen marcar una estrategia que se afirma a costa del principio de solidaridad, con el que se construyó la UE. Ojalá no sea así, y efectivamente se consiga una buena síntesis entre competitividad y solidaridad. Pero ¿qué antecedentes y argumentos proeuropeístas animan a fiarse de los actuales liderazgos europeos? $\dot{\imath} \mathrm{O}$ sólo cabe plegarse a las mayorías? Recordemos, al menos, que hemos dejado de lado opciones alternativas.

Ciertamente, se puede debatir hasta el agotamiento acerca del llamado modelo europeo. De hecho no sería más que el sumatorio (o quizás mejor, el mínimo común denominador: el modelo social común sería el que corresponde a los países

${ }^{16}$ Entrevista en Le Monde (23 de noviembre de 2004). 
menos avanzados) de los modelos vigentes en los Estados miembros, con algunos pequeños añadidos consensuados por unanimidad a lo largo de los años ${ }^{17}$. Con todas sus deficiencias e imperfecciones, dicho modelo es sin duda un avance más en el camino de las democracias sociales avanzadas, que tiene su origen en la postguerra, cuando el capital y el trabajo, la clase política y los ciudadanos, pactaron repartir el producto del rápido crecimiento económico, a cambio de la paz social y de la democracia.

Una vez más, recordar la historia puede ayudar. La creación del Mercado Común fue, entre otras cosas, un intento de aplicar y extender el modelo social a algunas dimensiones supranacionales (políticas comunes como la agrícola son casi tan antiguas como el propio Mercado Común; otras como las políticas de desarrollo regional, se fueron añadiendo poco a poco a medida que las circunstancias lo requerían). El crecimiento económico y la cohesión social deberían depender, básicamente, de las políticas nacionales. Sobre esta premisa se han reconocido distintos componentes económicos y sociales de los derechos de ciudadanía, así como los sistemas de educación, salud y bienestar social que, con obvias desigualdades entre países ricos y pobres, se han ido desarrollando durante los últimos cincuenta años.

Lo que entonces fue el resultado de la intuición de unos visionarios (los llamados "padres de Europa"), en el contexto actual de la globalización resulta aún más funcional. En efecto, se suele decir que la globalización diluye el carácter "nacional" de las relaciones sociales, los mercados y la políitica, y pone en cuestión el concepto tradicional de soberanía. De ahí la necesidad de pactos supranacionales ${ }^{18}$.

\footnotetext{
17 Sobre ese modelo existe una gran riqueza de análisis y reflexión. A título puramente indicativo recomendamos las siguientes lecturas: MICHEL ALBERT (1993) Capitalismo contra capitalismo, Buenos Aires/Barcelona/México, Paidós; JeREMY RifKIN (2004) El sueño europeo. Cómo la visión europea del futuro está eclipsando el sueño americano, Barcelona, Paidós; ANTHONY GIDDENS (2007) Europa en la era global, Barcelona, Paidós; DAVID HELD (2007) "Hacia un pacto global", Foreign Policy, edición española, http://www.fp-es.org/jun_jul_2004/story_3_10.asp (consulta realizada el 23 de noviembre de 2007). Cfr. HeLD, D. (2005) Un pacto global. La alternativa socialdemócrata al consenso de Washington, Madrid, Taurus.

${ }^{18}$ Esto se aplicaría también a los países en desarrollo. "En las incipientes democracias de los países en desarrollo, precisamente los más transnacionalizados y vulnerables, la globalización reduce el margen de maniobra para la acción política y las políticas de desarrollo, y los somete a los vaivenes de una economía global sin ataduras, en la que se incluyen redes transnacionales ilícitas que tratan de sortear o debilitar la jurisdicción estatal para mantenerse." Cf. José A. Alonso y José A. SANAHUJA, "Un mundo en transformación. Repensar la agenda de desarrollo", en INTERMON-OXFAM (2007) La realidad de la ayuda 2006-2007, Barcelona, Capítulo IV, p. 191.
} 
La solución de muchos de los problemas hoy planteados pasará seguramente -mediante la aplicación, nada sencilla, del principio de subsidiariedad- por una combinación de "más Europa", para aquellas cuestiones que lo requieran y "menos Europa" para muchas otras que pueden ser abordadas y resueltas a niveles más cercanos a los ciudadanos. Por eso, nuestro moderado europeísmo nace de la convicción de que "el Estado es demasiado pequeño para los grandes problemas de la vida y demasiado grande para los pequeños", parafraseando a Ulrich Beck. Estamos ante un proyecto político que no es ni será nunca un superestado, pero que es algo más que un área de cooperación intergubernamental ${ }^{19}$.

Todo esto está en perfecta consonancia con el consenso hoy creciente acerca de la necesidad de una redefinición del Estado y de la soberanía -lo que el mismo Ulrich Beck ha llamado el "Estado transnacional cooperativo"20-, para que la acción estatal se complemente con nuevas reglas e instituciones de gobernación supranacional. Se trata de una profunda redefinición de los conceptos de soberanía, de Estado y de ciudadanía, orientada hacia una ciudadanía global y cosmopolita. Como afirma David Held, "los pactos sociales nacionales son insuficientes para garantizar un equilibrio real entre los valores de la solidaridad social, la políitica de la democracia y la eficacia del mercado"21.

En este contexto, la construcción de la UE desborda sus propios límites. Como dice, precisamente, A. Giddens:

"La Unión Europea es diferente. La veo marcando un camino que podría ser, y seguramente será, seguido en otras zonas. Lo importante de la UE no es que esté localizada en Europa, sino que está explorando una forma de gobierno transnacional. Contrariamente a lo que dicen algunos de sus defensores y detractores, no es ni un Estado federal ni un super Estado-nación. Pero tampoco es simplemente una asociación de naciones. Los países que han entrado en la UE han renunciado voluntariamente a parte de su soberanía"22.

19 GIDDENS (2007), p. 267.

20 Citado por José A. Alonso y José A. Sanahuja, Op. cit. p. 192.

${ }^{21}$ Ibidem, p. 191.

22 Anthony GidDens (2000) Un mundo desbocado. Los efectos de la globalización en nuestras vidas, Madrid, Taurus. 


\section{Los retos del futuro: algunas tareas para la agenda europea}

Los debates sobre la fallida Constitución o sobre la próxima reforma de los Tratados dejan prácticamente intacta la agenda europea. Son muchos, y de diverso calado, los retos que tiene lo que podríamos denominar "la Europa pendiente". Sin ánimo de exhaustividad enumeramos a continuación algunos que nos parecen relevantes:

1. Ante todo, ratificar el nuevo Tratado, sean cuales fueren los defectos del proceso. Después de todo lo que llevamos dicho, podríamos concluir que se trata de un proceso que no debería plantear excesivos riesgos, pero nunca se sabe. En cualquier caso, que la ratificación se haga a buen ritmo y sin sobresaltos podría aportar fortaleza al proyecto europeo y contribuir a aliviar un cierto euroescepticismo actualmente vigente.

2. Activar los cambios institucionales previstos. A pesar de que los plazos previstos para su entrada en vigor son excesivamente largos, los cambios aludidos en las estructuras de gobierno de la Unión son esperanzadores: todos van en la línea de un funcionamiento más eficaz de las instituciones y de un reforzamiento de su imagen internacional. Queda -y no es pequeño reto-encontrar las personas adecuadas para los puestos clave, en una coyuntura en la que no abundan precisamente los liderazgos potentes. Ya nos referimos a ello.

3. Asimilar la ampliación. En muy poco tiempo (de 2003 a 2007) la UE ha pasado de 15 a 27 países, de 350 a casi 500 millones de habitantes (con la incorporación de 10 países en 2004 y otros 2 en 2007). Este rápido crecimiento en extensión no ha ido acompañado de un proceso paralelo de progreso en intensidad, ni en asimilación e identificación por los ciudadanos (los nuevos y los veteranos) de las implicaciones del fenómeno. La ampliación ha generado una expansión geográfica acompañada de un cambio en la tendencia a profundizar la integración: parece haber triunfado la propuesta británica apoyándose en la geoestrategia alemana. Viéndolo con la perspectiva de estos 4 años, la ampliación ha roto el principio de gradualismo. Agregar 12 socios de golpe ha puesto en peligro tanto los procesos institucionales como las políticas estructurales. Hay que aceptar la lógica expansiva de la UE y es obvio que no se podían quedar fuera. Pero ¿̇no cabe decir que "se nos ha atragantado la ampliación"? La única solución parece ser la cooperación reforzada o la Europa de varias velocidades, con una primera división y una segunda división: pero es importante que el criterio que ordene el proceso sea el interés por profundizar y no el de la renta per cápita ni el de la antigüedad en el proceso. 
Habría que proceder como se hizo con la unión monetaria. Ahora bien -y de nuevo citamos a Anthony Giddens-, "para que la UE florezca debe haber algo a lo que los ciudadanos puedan sentir que pertenecen y ese algo debe ser una comunidad"23.

4. Las fronteras de Europa. Lo que acabamos de decir conduce, sin duda, a preguntarnos cuáles serán las fronteras de la Unión, y también cuáles son las fronteras de Europa. ¿2Podrá seguir creciendo la UE indefinidamente? La expansión de la UE ¿̇es una cuestión puramente cuantitativa o es también cualitativa? ¿Depende sólo de la capacidad de integrar o tiene que ver con la definición y la delimitación de lo que es Europa? Naturalmente en seguida pensamos en Turquía. Y es lógico que, ante su posible incorporación, surjan preguntas. ¿ Basta guiarse por motivos políticos y geoestratégicos, como parece ser el proceder de algunos gobiernos de la Unión? Dónde está el límite de Europa no es una cuestión fácil de dilucidar. Por eso es más necesario sentarse a hablar de ello...

5. El reto de la globalización. Este nuevo escenario mundial va unido, según el parecer de muchos, al hecho de que la economía europea se está quedando rezagada con relación a la estadounidense. Se ha llegado a afirmar a este respecto -no sin exageración- que Francia, Italia y Alemania son "sociedades bloqueadas"24. Por esta razón el Consejo Europeo de Lisboa de marzo de 2000 adoptó un importante y ambicioso compromiso con el objetivo de convertir a la Unión Europea en la economía más dinámica y más competitiva del mundo en el horizonte de 2010 (acuerdo conocido como la Estrategia de Lisboa). En 2004 una comisión encabezada por Wim Kon realizó una revisión intermedia de la misma: los resultados hasta la fecha no son muy alentadores. ¿Cómo mejorar la competitividad de la economía europea sin renunciar al modelo "renano" del Estado social, con redes de seguridad para los ciudadanos y para las áreas más desfavorecidas, es decir con un alto grado de solidaridad interpersonal e interregional. El reto es, por tanto: ¿̇son compatibles el modelo social europeo y la necesidad de ser competitivos en una economía globalizada?25.

${ }^{23}$ GIDDENS (2007), p. 276.

${ }^{24}$ GIDDENS (2007), p. 53.

${ }^{25}$ Véanse las alusiones a este tema en nuestro anterior editorial: CONSEJO DE REDACCIÓN (2007) "La política económica del gobierno Zapatero: continuidad, cambio, nuevas incógnitas", Revista de Fomento Social, $n^{\circ} 247,293-318$. 
6. Consolidar el nuevo modelo de financiación, orientando adecuadamente los fondos en clave de solidaridad y competitividad. El periodo 2007-2013 se caracteriza, entre otras cosas, por la introducción de importantes, aunque graduales, modificaciones en la estructura de los presupuestos comunitarios, tanto desde el punto de vista de los gastos como de los ingresos. Estos cambios suponen, entre otras cosas, una modificación sustancial de los saldos por países, siendo precisamente España el país más afectado por la disminución de los flujos del presupuesto comunitario. En un anterior editorial analizamos este aspecto en profundidad; remitimos a nuestros lectores a dicho texto ${ }^{26}$. Se pretende que las políticas sectoriales (como la tradicional agraria) y las estructurales (más orientadas a la cohesión) sean una especie de palanca para la modernización y adaptación de la economía europea a las nuevas realidades de la competencia global. En síntesis, se trataría de transformar el presupuesto común (superior a los 100.000 millones de euros al año) en un instrumento eficaz al servicio de esa mezcla de competitividad, cooperación y solidaridad, que siempre han sido las claves de los avances del proyecto europeo.

7. Ultimar las reformas de la Política Agrícola Común (PAC)..., "la reforma de la reforma". Aunque ya la mencionamos en el apartado anterior, por su entidad y por los profundos cambios a que se está viendo sometida, merece un pequeño epígrafe aparte. Ya hemos tratado del tema en algún editorial anterior ${ }^{27}$. Es esta una tarea siempre en marchay siempre por acabar. Que la PAC tradicional debía ser reformada es algo de lo que los europeos venimos oyendo hablar desde hace varios lustros. Sucesivos e importantes cambios se han ido introduciendo sin que, aparentemente, se avizore en el horizonte lo que pudiera llamarse una "solución final". La impopularidad de esta política es bien conocida por los efectos negativos para muchos de los países terceros, tanto desarrollados como empobrecidos. Precisamente en estas fechas es noticia el bloqueo de las negociaciones de la Ronda Doha de la Organización Mundial del Comercio, debido esencialmente a la falta de acuerdo sobre esta importante cuestión.

8. La Unión Monetaria constituye hoy un elemento totalmente consolidado del modelo europeo. Sin embargo, no faltan incongruencias e incertidumbres en su

${ }^{26}$ Cf. CONSEJO DE REDACCIÓN (2006) "La financiación de la Unión Europea: los límites de una ambición", Revista de Fomento Social, $n^{\circ}$ 242, abril-junio, 139-164.

${ }^{27}$ Cf. CONSEJO dE ReDACCIÓN (2001) "La política agraria común en un mundo globalizado", Revista de Fomento Social, $n^{\circ} 222,334-367$. A pesar de las reformas posteriores, las ideas de fondo de aquel texto siguen estando vigentes. 
evolución y funcionamiento. Incongruencias, en la medida en que la aplicación del famoso pacto de estabilidad ${ }^{28}$ ha sido una auténtica carrera de obstáculos, hasta transformar las excepciones en reglas, precisamente porque los incumplimientos vinieron de países muy importantes (como Francia y Alemania). Aunque se han dado pasos hacia la reforma de este Pacto, todavía hay cuestiones por cerrar. Hablamos también de incertidumbre, porque son muchos aún los países que no han asumido el euro, algunos de los cuales pertenecen al núcleo duro de los 15 que firmaron el Tratado de Maastricht, y es difícil concebir que una tal situación se pueda prolongar indefinidamente; incertidumbre también, porque la evolución de nuestra moneda común con respecto al dólar (que se ha ido debilitando de forma continuada) plantea graves problemas a la capacidad exportadora de las empresas de la UE y genera muchas dudas acerca de cuál va a ser el futuro del sistema monetario mundial, caracterizado -entre otras cosas- por unos precios del petróleo que ya han superado el umbral de los 100 dólares por barril29.

9. Por último, un reto de enorme envergadura para la UE consiste en afrontar, como bloque potente, los retos mundiales. Nuestro continente da una impresión de clara debilidad en el escenario de los grandes conflictos mundiales. Basando su estrategia en el diálogo y la negociación frente al modo más rudo de las intervenciones de los Estados Unidos (Venus contra Marte, como se ha escrito), pareciera que la UE deja "el trabajo sucio" a los socios norteamericanos, entre otras cosas por su enorme superioridad militar. Definir su lugar en el mundo, en particular frente a los Estados Unidos, e intervenir más decisivamente aportando soluciones efectivas a los conflictos bélicos, sobre todo los cercanos a su territorio, es una de las mayores tareas pendientes. Hay toda una dialéctica EEUU-Europa que se puso especialmente de manifiesto en la grave fractura ocurrida entre los socios europeos con ocasión de la guerra de lrak. Y se nos suele acusar, no sin razón, de carecer de un liderazgo claro ("Europa, humm... ¿quién se pone al teléfono?", como solía decir sarcásticamente Henry Kissinger).

${ }^{28}$ Consecuencia del Tratado de Maastricht que lanza el proceso de la Unión Monetaria, el Pacto de Estabilidad consiste en un compromiso de los países miembros de la zona euro de respetar ciertas disciplinas macroeconómicas que se consideraron imprescindibles para garantizar la estabilidad y la solvencia de la nueva moneda; la norma más controvertida es la obligación de los países de moderar sus déficits públicos, bajo pena de multas importantes en caso de incumplimiento. No es este el lugar de detallar sus mecanismos concretos.

${ }^{29}$ Veánse al respecto nuestras reflexiones editoriales: CONSEJO DE REDACCIÓN (2004), "De nuevo el petróleo", Revista de Fomento Social, n 235, 491-520; CONSEJO dE REDACCIÓN (2007), "Claves para comprender la crisis financiera internacional", Revista de Fomento Social, n 248, 515-535. 
Iniciábamos este editorial con un texto desafiante de Anthony Giddens. Desde una perspectiva más humanista, lo terminamos con una reflexión muy pertinente del pensador italiano Claudio Magris:

"La unidad europea no debe infundir temor. De hecho, vivimos ya en una realidad que no es nacional, sino europea; esta unidad europea de facto tendrá que convertirse cada vez más en una unidad institucional, aunque el camino esté plagado de dificultades y de momentáneos retrasos. El amor por Europa no presupone ninguna miope soberbia eurocéntrica: el centro del mundo hoy está en cualquier parte y no tolera ningún inicuo dominio de una parte del mundo" 30 .

30 Claudio Magris (2004) "Discurso de recepción del premio Príncipe de Asturias de Letras de 2004", El País, 23 de octubre, 38. 